\title{
Optical Coherence Tomography-Guided Femtosecond LASIK in the Setting of Corneal Scarring
}

\author{
Sloan W Rush ${ }^{1,2}$ \\ Ryan B Rush (iD) $1-3$ \\ 'Panhandle Eye Group, Amarillo, TX, \\ 79106, USA; ${ }^{2}$ Texas Tech University \\ Health Science Center, Department of \\ Surgery, Amarillo, TX, 79106, USA; \\ ${ }^{3}$ Southwest Retina Specialists, Amarillo, \\ TX, 79106, USA
}

Purpose: To report the outcomes of femtosecond-assisted laser in situ keratomileusis (LASIK) in patients with previous corneal scarring using optical coherence tomography (OCT) imaging to determine flap depths.

Methods: The charts of 11 eyes of 9 patients with previous off-visual axis corneal scarring that underwent femtosecond LASIK using OCT guidance for flap depth determination were retrospectively reviewed at a single private practice institution. The baseline characteristics, intraoperative findings and postoperative outcomes were analyzed.

Results: All 11 eyes underwent femtosecond laser flap creation and LASIK without any significant intraoperative complications. Uncorrected visual acuity improved postoperatively $(p<0.0001)$ and remained stable at 3 months follow-up. None of the subjects lost any lines of best spectacle corrected visual acuity or developed any flap complications during the postoperative period.

Conclusion: The OCT-guided femtosecond laser technique described in this report can provide a safe and effective method to deliver LASIK in the setting of previous corneal scarring. Future investigations are required to further validate the findings in this study.

Keywords: LASIK, corneal scarring, optical coherence tomography

\section{Introduction}

Modern laser in situ keratomileusis (LASIK) has become one of the safest and most effective refractive procedures available. ${ }^{1}$ Advancements in technology that have contributed to the increased safety and efficacy of LASIK includes the use of femtosecond lasers for flap creation, ${ }^{2}$ development of wavefront excimer laser technology, ${ }^{3}$ and utilization of new imaging modalities to more effectively screen for corneal ectasia disorders. ${ }^{4,5}$ With corneal ulcers and trauma with corneal foreign bodies being among the most common reasons for eye-related emergency department visits, ${ }^{6}$ many patients may present for refractive surgery evaluation that have existing corneal scarring. Previous studies have described the benefits of phototherapeutic keratectomy for treatment of more advanced corneal scarring involving the central visual axis, a scenario in which LASIK may be contraindicated. ${ }^{7}$ Several authors have also described safe femtosecond LASIK techniques in the setting of previous radial keratotomy through the radial incision scars. ${ }^{8,9}$ In the setting of peripheral corneal scarring from other causes, there still remains some concern about the potential for flap complication which may include flap buttonholes, incomplete flaps or even split flaps. ${ }^{10}$
Correspondence: Ryan B Rush Southwest Retina Specialists, 741I Wallace Blvd., Amarillo, TX, 79106, USA Tel +1806 35I-1870

Email ryan.rush.md@gmail.com 
To our knowledge, there are currently no reports demonstrating an effective technique for creating a femtosecond laser flap in patients with underlying peripheral corneal scarring. In this study, we report a consecutive series of patients with off visual axis corneal scarring that underwent femtosecond LASIK using OCT guidance to determine the appropriate flap depths.

\section{Methods}

The SRS Institutional Review Board (IRB00009122) approved this retrospective, case series of patients with corneal scarring that received LASIK treatment from July 2015 through July 2018 at a single private practice institution in Amarillo, TX. All components of the study adhered to the tenets of the Declaration of Helsinki and were performed in accordance with human research standards and regulations. Informed consent was not required according to the SRS Institutional Review Board guidelines on retrospective studies without patient identifying information.

The operative eyes of 9 consecutive patients with existing peripheral corneal scarring that underwent femtosecond LASIK using a standardized OCT guidance technique to determine flap depth on the Wavelight FS200 femtosecond laser and the Wavelight EX500 excimer laser platforms (Alcon, Fort Worth, TX, USA) were included. The demographic and preoperative data were collected at baseline from each subject including gender, age, uncorrected visual acuity (UCVA), best spectacle corrected visual acuity (BSCVA), manifest refraction spherical equivalent and refractive astigmatism and corneal pachymetry. The corneal pachymetry was measured by optical coherence tomography (OCT) with the Cirrus HDOCT (Carl Zeiss Meditec, Inc, Dublin, California, USA). Intraoperative details (including ultrasonic pachymetry of the stromal bed after flap retraction) and any intraoperative or postoperative complications were recorded for each case. The UCVA, BSCVA and refractive measurements were collected postoperatively at $3( \pm 1)$ weeks and 3 $( \pm 0.5)$ months follow-up. The JMP 11 software from the SAS Institute (Cary, NC, USA) was used to calculate means and standard deviations. One-way analysis of the variance was used to compare pre- and postoperative means, and results were considered statistically significant at the alpha $<0.05$ level.

\section{Patient Selection Criteria}

Patients included in the study were otherwise good candidates for refractive surgery but had developed corneal scarring with stromal extension from either a previous corneal ulcer or a previous corneal trauma. The opacity could be no more than $50 \%$ depth of total cornea pachymetry and was restricted to maximum dimensions of $3 \times 3 \mathrm{~mm}$. No portion of the corneal scarring was located in the central $3 \mathrm{~mm}$ optic zone, but all study patients would have at least some portion of the scarring contained within a $9.0 \mathrm{~mm}$ flap diameter. Exclusion criteria included the inability of the laser to track the pupil due to opacity. Preoperative BSCVA in the operative eye had to be $0.2 \log$ MAR or better. None of the scars had neovascularization present.

\section{OCT Measurements}

Multiple high-definition corneal OCT images were used to determine the preoperative location, extent and depth of the corneal scarring. Manual electronic caliper was used to measure the depth of the corneal scarring at its greatest dimension. Signal strength of 8 or greater was required for the image to be used in the calculations.

\section{Femtosecond Laser Settings}

The enhanced femtosecond laser power settings used for flap creation in all of the study patients have been described in previous investigations. ${ }^{11}$ In summary, the settings were as follows: Bed Cut Energy $=1.4 \mu \mathrm{J}$, Bed Cut Spot Separation $=6.0 \mu \mathrm{m}$, Bed Cut Line Separation $=6.0 \mu \mathrm{m}$, Side Cut Energy $=0.8 \mu \mathrm{J}$, Side Cut Spot Separation $=5.0 \mu \mathrm{m}$ and Side Cut Line Separation $=3.0 \mu \mathrm{m}$. A $9.0 \mathrm{~mm}$ flap diameter with a $70^{\circ}$ side cut angle and superior hinge was created in each case. The flap depth varied according to the preoperative OCT measurements of the total central corneal thickness and the OCT-identified maximum depth of the corneal scarring. The target flap depth was selected to be exactly 20 microns deeper than the maximum depth of scarring with 110 microns being the minimum depth. If the target flap depth was calculated to leave less than 300 microns of anticipated central residual stromal bed tissue post-excimer laser photoablation, then LASIK was not offered as an option. Figure 1 demonstrates a case study with photos using this technique.

\section{Surgical Technique}

A femtosecond flap retractor (Thorlakson Z-LASIK Flap Lifter, Katena Products, Inc, Denville, NJ) was used to open the side cut at an inferior portion of the flap away from the hinge. After establishing an 


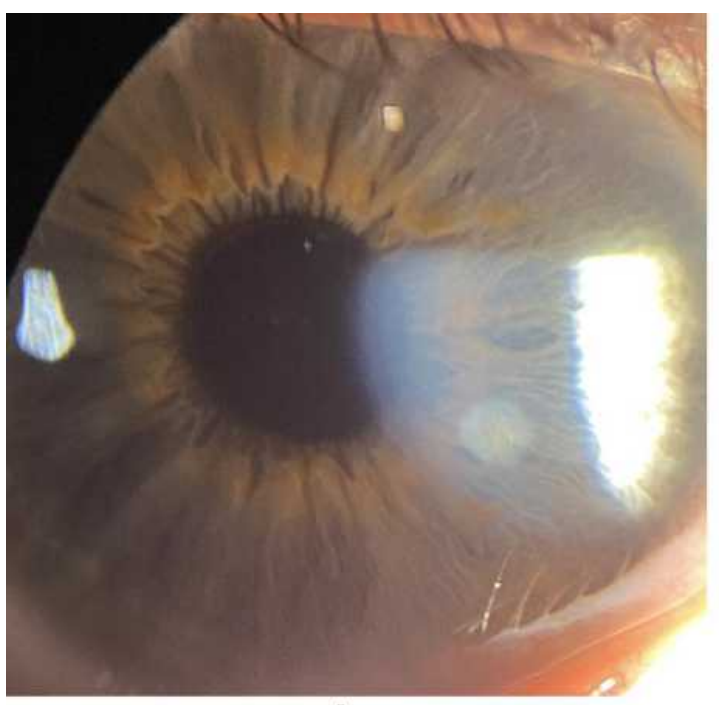

A

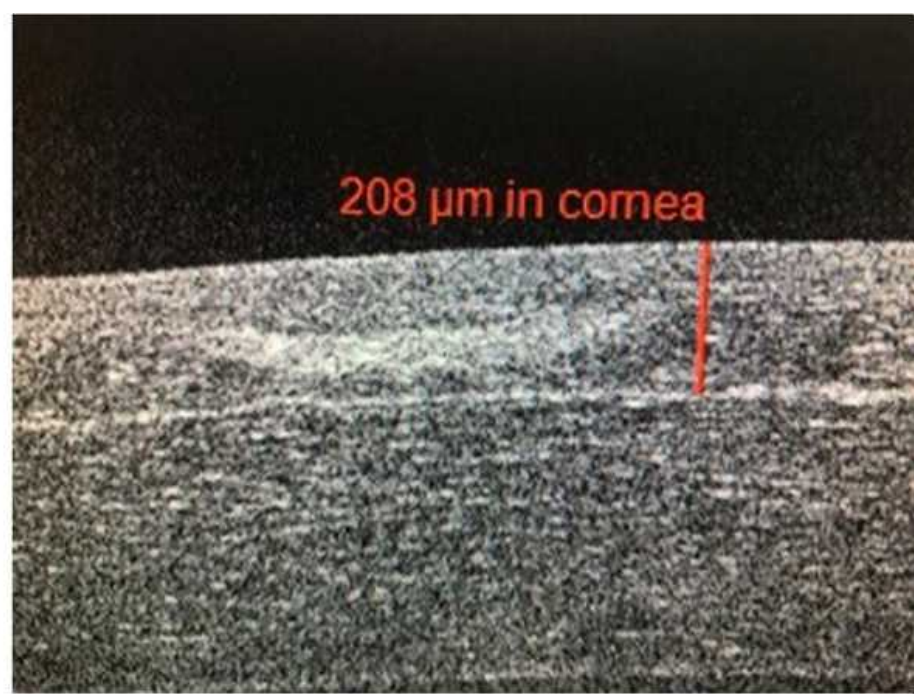

B

Figure I OCT-guided femtosecond LASIK in the setting of previous corneal scarring. (A) Pre-operative slit lamp photo of a patient with history of a traumatic corneal foreign body injury. The opacity was located in the mid-peripheral cornea and measured $1.5 \times 1.5 \mathrm{~mm}$. (B) One-day post-operative OCT corneal image of the same patient demonstrating maximum depth of the opacity at 180 microns for which the intended flap depth was aimed at 200 microns.

opening into the stromal plane, the side cut dissection was propagated along the inferior flap margin. The inferior portion of the flap was then retracted and inverted. A Merocel (Medtronic, PLC, Minneapolis, $\mathrm{MN}$ ) fiber-free sponge was used to carefully retract the rest of the flap toward the hinge. The stromal bed thickness was measured by the ultrasonic pachymetry device on the Wavelight EX500 immediately after the new flap was lifted but prior to the excimer laser photoablation treatment. After excimer laser photoablation treatment, the flap was repositioned with a blunt tipped 30-gauge cannula on syringe with Balanced Salt Solution (Alcon, Inc, Fort Worth, TX).

\section{Results}

There were 11 eyes of 9 subjects that were included in the analysis with 3-month follow-up data. A summary of the baseline characteristics and demographic features is presented in Table 1. All patients developed corneal scarring from either previous corneal ulcer $(n=3)$ or previous traumatic corneal injury $(n=8$, five of which were related to embedded metallic foreign bodies that had to be removed). There were no cases in which suction was either lost or could not be obtained. All flaps were able to be lifted without complication or notable adhesion/resistance at the site of the corneal scarring. Figures 2 and 3 detail a case study from this series demonstrating the

Table I OCT-Guided Femtosecond LASIK in the Setting of Previous Corneal Scarring: Baseline Characteristics and Demographic Features of the Study Population

\begin{tabular}{|l|l|}
\hline Preoperative Characteristics and Demographics (n=I I Eyes) & Means with (Standard Deviations) \\
\hline Age (years) & 42.1 (I2.9), Range $=22$ to 57 \\
\hline Gender & $72.7 \%$ Male and $27.3 \%$ Female \\
\hline Preoperative uncorrected visual acuity (logMAR) & $0.97(0.25)$, Range $=0.5$ to I.3 \\
\hline Preoperative best spectacle corrected visual acuity (logMAR) & 0.02 (0.06), Range $=0$ to 0.2 \\
\hline Preoperative Refractive Error Spherical Equivalent (diopters) & -1.55 (3.68), Range $=-7.75$ to +5.625 \\
\hline Preoperative Refractive Astigmatism (diopters) & 0.97 (0.98), Range $=0$ to 3.5 \\
\hline Optical Coherence Tomography-measured Preoperative Total Corneal Thickness (microns) & 549.0 (42.5), Range $=492$ to 622 \\
\hline Optical Coherence Tomography-measured Preoperative Maximum Depth of Corneal Scarring (microns) & 99.5 (39.5), Range $=60$ to I60 \\
\hline
\end{tabular}




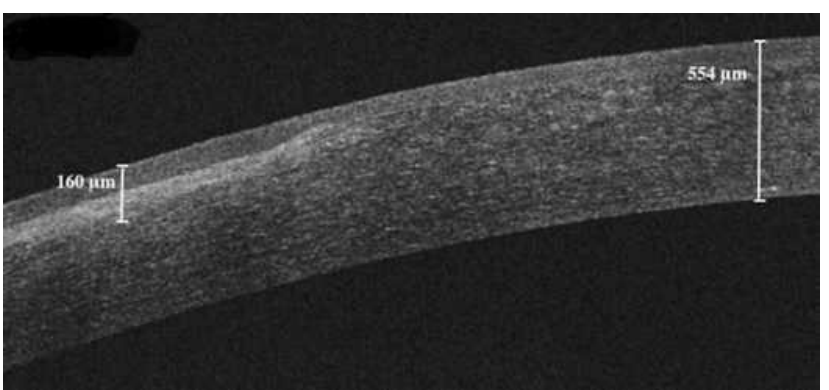

Figure 2 OCT-guided femtosecond LASIK in the setting of previous corneal scarring. Preoperative OCT corneal image of a 46-year-old male with inferior peripheral corneal scarring due to a previous contact lens-related corneal ulcer. Manual electronic caliper (white lines) measured the maximum depth of the corneal scar at 160 microns and total corneal pachymetry of 554 microns. A femtosecond flap depth of 180 microns was selected avoid this area of fibrosis.

OCT-guided calculation of flap depth as well as the preand postoperative corneal topographies.

The mean intended flap depth for the study population was $137.3 \pm 32.6$ microns with range of 110 to 200 microns. Based on intraoperative ultrasonic pachymetry

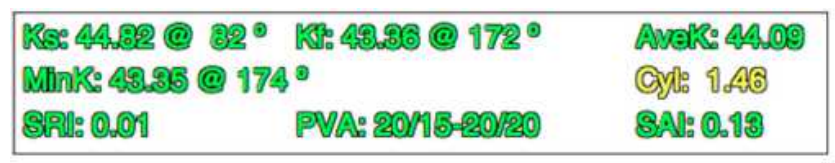

A

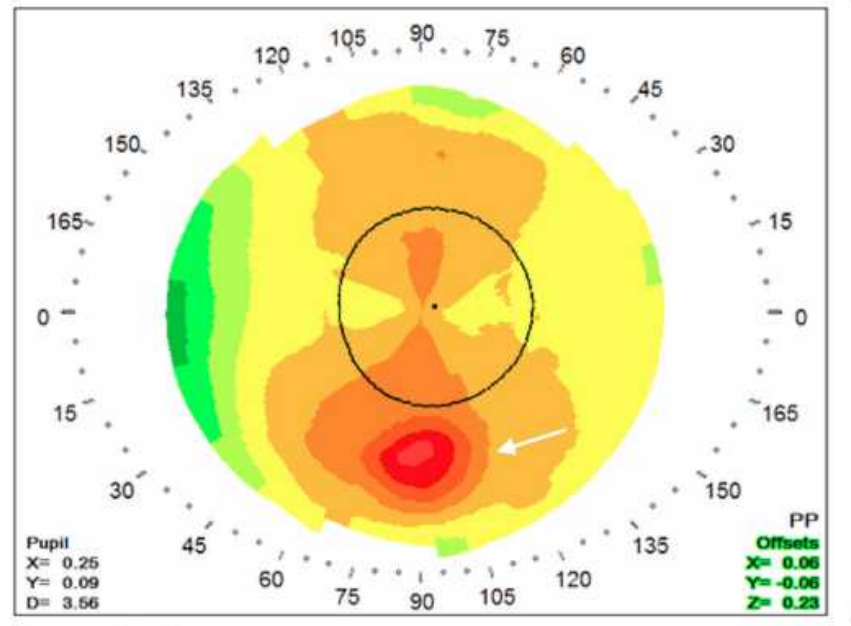

measurements of the stromal bed after flap retraction, the calculated percentage error for actual femtosecond laser flap depth versus targeted flap depth was $4.5 \pm 12.2 \%$. UCVA significantly improved from the baseline level to the 3-month postoperative follow-up $(\mathrm{p}<0.0001)$. The postoperative outcomes are summarized in Table 2. No refractive shifts or regression $>0.5 \mathrm{D}$ spherical equivalent was noted over the course of follow-up, and there were no eyes that lost one or more lines of BSCVA at the final follow-up visit. There were no cases of diffuse lamellar keratitis or epithelial ingrowth. No patients required postoperative re-floating or re-positioning of the flap.

\section{Discussion}

To our knowledge, this is the first case series to report successful use of the femtosecond laser to create a flap in the setting of corneal scarring. The efficacy and predictability of this technique in terms of visual results shows outcomes comparable to previously reported studies using

\section{Standard}

Rush

\begin{tabular}{|c|c|c|}
\hline & \\
\hline & & \\
\hline \multicolumn{2}{|c|}{ 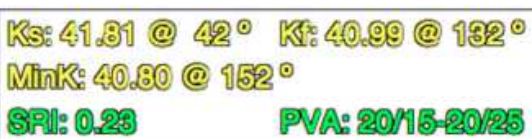 } & BA: 0.27 \\
\hline
\end{tabular}

B

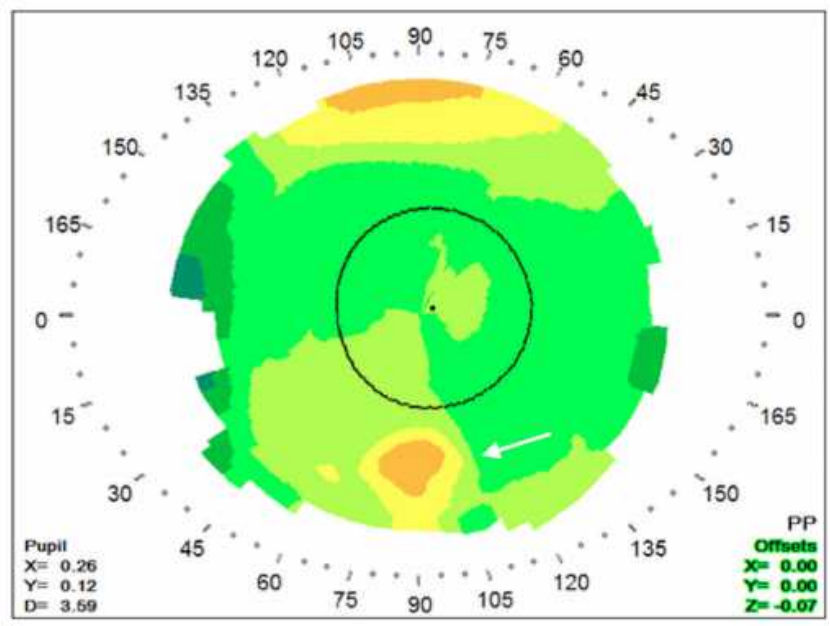

Diopters

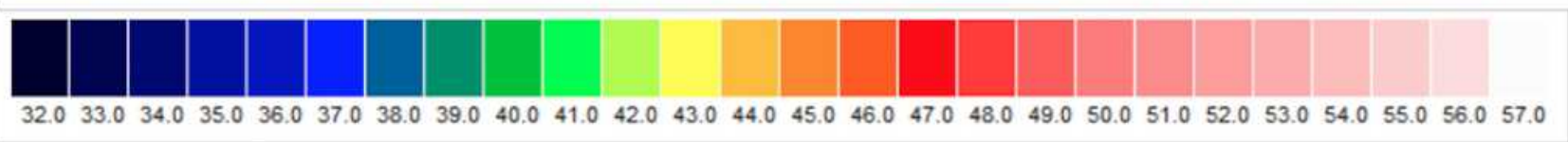

Figure 3 OCT-guided femtosecond LASIK in the setting of previous corneal scarring. (A) Preoperative corneal topography of the same 46-year-old male in Figure I showing a relatively regular corneal shape, but with a small visible inferior round focus of irregularity off the visual axis (white arrow) that corresponded with the location of the circular corneal scarring that was seen on clinical exam. The preoperative BSCVA for this patient was 20/20. (B) Postoperative corneal topography of the same patient showing flatter corneal curvature after LASIK treatment with $-4.00+1.50 \times 095$. The small round inferior focus of scarring which was contained wholly in the flap is still barely visible (white arrow). The postoperative UCVA was 20/I5. 
Table 2 OCT-Guided Femtosecond LASIK in the Setting of Previous Corneal Scarring: Postoperative Outcomes

\begin{tabular}{|l|l|}
\hline Postoperative Outcomes ( $\mathbf{n}=$ I I Eyes) & Means with (Standard Deviations) \\
\hline Postoperative uncorrected visual acuity (logMAR) & 0.03 (0.09), Range $=-0.1$ to 0.2 \\
\hline Postoperative best spectacle corrected visual acuity (logMAR) & -0.01 (0.03), Range $=-0.1$ to 0 \\
\hline Postoperative Refractive Error Spherical Equivalent (diopters) & 0.07 (0.16), Range $=0$ to 0.5 \\
\hline Postoperative Refractive Astigmatism (diopters) & 0.05 (0.10), Range $=0$ to 0.25 \\
\hline Calculated Percentage Error for Femtosecond Laser Flap Depth (\%) & 4.5 (I2.2), Range $=0$ to 22.1 \\
\hline
\end{tabular}

femtosecond LASIK in otherwise healthy eyes without corneal scarring where $>95 \%$ of all treated eyes achieve both postoperative spherical equivalent and postoperative astigmatism within $0.5 \mathrm{D}$ from the intended refractive target. ${ }^{12}$ Femtosecond LASIK is an important refractive treatment modality to have available because not every patient desires or is a good candidate for PRK. While some investigators have successfully treated corneal scarring from using topography-guided $\mathrm{PRK},{ }^{13}$ but there is literature that suggests that patients with existing corneal scarring have corneal stroma that may already contain mature myofibroblasts that could pose significant risk for postoperative haze formation in setting of PRK. ${ }^{14,15} \mathrm{de}$ Rojas Silva et al have previously described LASIK using a mechanical microkeratome in the setting of previous herpes simplex keratitis. ${ }^{16}$ However, the eyes in this study had primarily epithelial disease without corneal stromal scarring. Also, one of the principal advantages of the femtosecond laser over the mechanical microkeratome is that more flexible and accurate flap depths can achieved. ${ }^{17}$ OCT imaging of the corneal scarring allows for the surgeon to identify the full depth of the $\operatorname{scar}^{18}$ and to adjust the femtosecond laser flap depth accordingly to a deeper location away from the scar to reduce the likelihood of complications such as buttonholed, incomplete or split flaps. ${ }^{19}$

We caution that standard femtosecond laser flap settings used during LASIK leave residual stromal tissue bridges behind that must be manually separated when lifting the flap. We believe that the modified femtosecond laser settings used in this study allow for a safer, less traumatic lifting of the flap on these eyes that already have compromised structural integrity from their previous scarring. The modified femtosecond laser settings used in this study were originally developed in the setting of eyes with previous RK incisions in order to produce a femtosecond laser generated flap that lifted similarly to a mechanical microkeratome generated flap in that it could be lifted with minimal or no resistance. ${ }^{11}$ More investigations will be required to determine to optimal femtosecond laser settings to use when creating flaps on corneas containing scar tissue.

Weaknesses of this study include its retrospective study design, the lack of a control group, the small number of cases, and the relatively short follow-up interval. Future investigations will be necessary to validate the femtosecond LASIK technique described in this study in subjects with previous corneal scarring and ultimately compare the outcomes to other treatment modalities such as traditional PRK or transepithelial PRK.

\section{Abbreviations}

OCT, optical coherence tomography; LASIK, laser in situ keratomileusis; BSCVA, best spectacle-corrected visual acuity; UCVA, uncorrected visual acuity.

\section{Data Sharing Statement}

The datasets used and/or analyzed during the current study are available from the corresponding author on reasonable request.

\section{Ethics}

The study was approved by the SRS Institutional Review Board in accordance with the Ethical Standards laid down in the Declaration of Helsinki.

\section{Acknowledgment}

This study was presented at the 2017 ASCRS meeting during a paper session.

\section{Author Contributions}

All authors made substantial contributions to conception and design, acquisition of data, or analysis and interpretation of data; took part in drafting the article or revising it critically for 
important intellectual content; agreed to submit to the current journal; gave final approval of the version to be published; and agree to be accountable for all aspects of the work.

\section{Funding}

There is no funding to report.

\section{Disclosure}

The authors report no conflicts of interest in this work.

\section{References}

1. Sandoval HP, Donnenfeld ED, Kohnen T, et al. Modern laser in situ keratomileusis outcomes. J Cataract Refract Surg. 2016;42 (8):1224-1234. doi:10.1016/j.jcrs.2016.07.012

2. Huhtala A, Pietilä J, Mäkinen P, Uusitalo H. Femtosecond lasers for laser in situ keratomileusis: a systematic review and meta-analysis. Clin Ophthalmol. 2016;10:393-404. doi:10.2147/OPTH.S99394

3. Chen LY, Manche EE. Comparison of femtosecond and excimer laser platforms available for corneal refractive surgery. Curr Opin Ophthalmol. 2016;27(4):316-322. doi:10.1097/ICU.0000000000000268

4. Saad A, Gatinel D. Combining placido and corneal wavefront data for the detection of forme fruste keratoconus. J Refract Surg. 2016;32 (8):510-516. doi:10.3928/1081597X-20160523-01

5. Randleman JB, Dupps WJ Jr, Santhiago MR, et al. Screening for keratoconus and related ectatic corneal disorders. Cornea. 2015;34 (8):e20-e22. doi:10.1097/ICO.0000000000000500

6. Channa R, Zafar SN, Canner JK, et al. Epidemiology of eye-related emergency department visits. JAMA Ophthalmol. 2016;134 (3):312-319. doi:10.1001/jamaophthalmol.2015.5778

7. Rush SW, Matulich J, Rush RB. Long-term outcomes of optical coherence tomography-guided transepithelial phototherapeutic keratectomy for the treatment of anterior corneal scarring. $\mathrm{Br} J$ Ophthalmol. 2014;98 (12):1702-1706. doi:10.1136/bjophthalmol-2014-305366

8. Leccisotti A, Fields SV. Femtosecond-assisted laser in situ keratomileusis for consecutive hyperopia after radial keratotomy. J Cataract Refract Surg. 2015;41(8):1594-1601. doi:10.1016/j.jcrs.2015.08.014

9. Rush SW, Rush RB. One-year outcomes of femtosecond laser-assisted LASIK following previous radial keratotomy. J Refract Surg. 2016;32 (1):15-19. doi:10.3928/1081597X-20151207-07
10. Romero-diaz-de-leon L, Serna-Ojeda JC, Navas A, et al. Intraoperative flap complications in LASIK surgery performed by ophthalmology residents. J Ophthalmic Vis Res. 2016;11 (3):263-267. doi:10.4103/2008-322X.188393

11. Rush SW, Rush RB. Femtosecond laser flap creation for laser in situ keratomileusis in the setting of previous radial keratotomy. Asia Pac $J$ Ophthalmol. 2015;4(5):283-285. doi:10.1097/APO.000000000 0000131

12. Moussa S, Dexl A, Krall EM, et al. Comparison of short-term refractive surgery outcomes after wavefront-guided versus non-wavefront-guided LASIK. Eur $J$ Ophthalmol. 2016;26 (6):529-535. doi:10.5301/ejo.5000882

13. Sorkin N, Einan-Lifshitz A, Boutin T, et al. Topography-guided photorefractive keratectomy in the treatment of corneal scarring. $J$ Refract Surg. 2017;33(9):639-644. doi:10.3928/1081597X20170718-03

14. Torricelli AA, Santhanam A, Wu J, et al. The corneal fibrosis response to epithelial-stromal injury. Exp Eye Res. 2016;142:110-118. doi:10.1016/j.exer.2014.09.012

15. Ang BC, Foo RC, Lim EW, et al. Risk factors for early-onset corneal haze after photorefractive keratectomy in an Asian population: outcomes from the Singapore armed forces corneal refractive surgery programme 2006 to 2013. J Cataract Refract Surg. 2016;42 (5):710-716. doi:10.1016/j.jcrs.2016.01.047

16. de Rojas Silva V, Rodríguez-Conde R, Cobo-Soriano R, et al. Laser in situ keratomileusis in patients with a history of ocular herpes. $J$ Cataract Refract Surg. 2007;33(11):1855-1859. doi:10.1016/j. jcrs.2007.07.014

17. Xia L-K, Yu J, Chai G-R, et al. Comparison of the femtosecond laser and mechanical microkeratome for flap cutting in LASIK. Int $J$ Ophthalmol. 2015;8(4):784-790. doi:10.3980/j.issn.22223959.2015.04.25

18. Rush SW, Han DY, Rush RB. Optical coherence tomography-guided transepithelial phototherapeutic keratectomy for the treatment of anterior corneal scarring. Am $J$ Ophthalmol. 2013;156 (6):1088-1094. doi:10.1016/j.ajo.2013.06.026

19. Jadav DS, Desai N, Taylor KR, et al. Visual outcomes after femtosecond laser in situ keratomileusis flap complications. $J$ Cataract Refract Surg. 2015;41(11):2487-2492.
Clinical Ophthalmology

\section{Publish your work in this journal}

Clinical Ophthalmology is an international, peer-reviewed journal covering all subspecialties within ophthalmology. Key topics include: Optometry; Visual science; Pharmacology and drug therapy in eye diseases; Basic Sciences; Primary and Secondary eye care; Patient Safety and Quality of Care Improvements. This journal is indexed on PubMed

\section{Dovepress}

Central and CAS, and is the official journal of The Society of Clinical Ophthalmology (SCO). The manuscript management system is completely online and includes a very quick and fair peer-review system, which is all easy to use. Visit http://www.dovepress.com/ testimonials.php to read real quotes from published authors. 